\title{
Perancangan Apartemen Produktif dengan Pendekatan Arsitektur Hibrid
}

\author{
Nashihatul Barrit dan Arina Hayati \\ Departemen Arsitektur, Fakultas Arsitektur, Desain dan Perencanaan, Institut Teknologi Sepuluh Nopember (ITS) \\ e-mail: arina_h@arch.its.ac.id
}

\begin{abstract}
Abstrak - Di Indonesia, wilayah peri-urban menjadi salah satu wilayah dengan konversi lahan atau alih fungsi lahan pertanian tertinggi. Fenomena ini terjadi karena tingginya pertumbuhan penduduk dan peningkatan pembangunan fasilitas sarana dan prasarana di wilayah tersebut. Kondisi ini menyebabkan kurangnya lahan hijau yang produktif, namun tidak bisa dipungkiri kebutuhan akan hunian semakin meningkat. Untuk itu, perancangan arsitektur ini bertujuan merancang sebuah apartemen yang mengakomodasi antara aktivitas berhuni dan aktivitas yang mempertahankan produktivitas lahan. Pendekatan perancangan yang digunakan adalah pendekatan Arsitektur Hibrid. Hibridisasi diterapkan pada penggabungan antara dua aktivitas yaitu berhuni dan aktivitas yang mendukung produktifitas lahan (berkebun). Kedua hibridisasi menjadi konsep utama untuk membuat bangunan multifungsi dalam satu kesatuan bangunan. Metode hibrid yang digunakan dalam perancangan ini adalah Thematic Program dan Fabric Form. Dalam proses awal perancangan, bangunan apartemen produktif ini terbentuk berdasarkan pelaku dan aktivitas-aktivitas yang dilakukan di dalam bangunan. Kemudian, beberapa aktivitas yang terkait membentuk sebuah ruang-ruang hibrid yang dapat mengakomodasi berbagai macam aktivitas dalam waktu bersamaan. Penggabungan program secara Thematic memberikan kesan bagi pengguna bangunan akan kedekatannya dengan alam dan tumbuhan. Sehingga, selain mengakomodasi kebutuhan akan hunian, apartemen produktif ini dapat menjadi bangunan yang mneyediakan area terbuka produktif.
\end{abstract}

Kata Kunci--apartemen; area hijau produktif; arsitektur hibrid; konversi lahan; peri-urban

\section{PENDAHULUAN}

$\mathrm{K}$ ONVERSI lahan adalah perubahan fungsi sebagian atau seluruh kawasan lahan dari fungsi semula menjadi fungsi lain yang cenderung berdampak negatif terhadap lingkungan dan potensi lahan itu sendiri [1]. Menurut data Badan Pusat Statistik tercatat bahwa alih fungsi lahan pertanian untuk kepentingan lainnya selama 2002-2010 mencapai rata-rata 56.000-60.000 hektar per tahun. Data juga menunjukkan terdapat 48,96\% alokasi konversi lahan pertanian digunakan untuk sektor perumahan dan permukiman, 8,21\% sektor industri, $14,55 \%$ sektor perusahaan/perkantoran, dan 28,29\% untuk sektor lain [2]. Konversi lahan ini secara tidak langsung dipengaruhi oleh perubahan struktur ekonomi, pertumbuhan penduduk, arus urbanisasi dan konsistensi implementasi rencana tata ruang. Dampak negatif dari permasalahan ini menyebabkan berkurangnya luas lahan produktif termasuk lahan pertanian dan perkebunan yang mengganggu tercapainya swasembada pangan (Gambar 1).
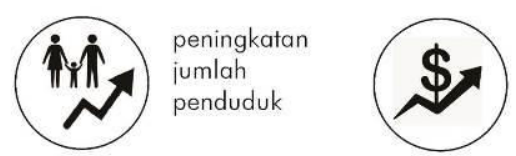

peningkatan dan perubahan struktur ekonomi ke arah revolusi industri

sehingga teriadi pembangunan di berbagai sektor
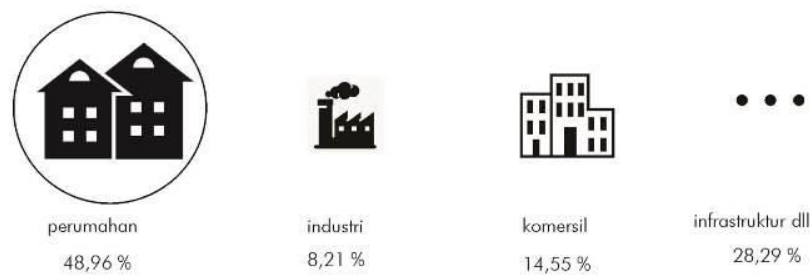

Gambar 1. Konversi Lahan untuk Sektor Lain.

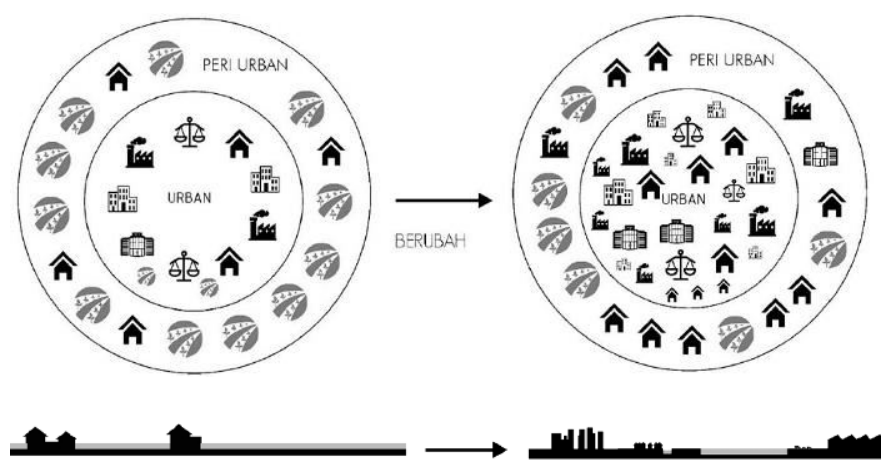

Gambar 2. Perkembangan Wilayah Peri-urban.

keadaan sekarang

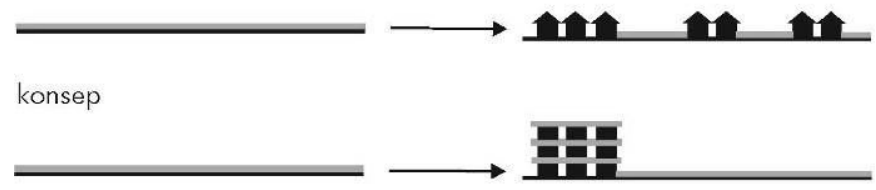

Gambar 3. Permasalahan Desain.

Perancangan arsitektur ini bertujuan untuk merancang sebuah hunian vertikal yang memiliki lahan hijau poduktif di konteks wilayah peri-urban. Konteks ini dipilih karena daerah perkotaan merupakan tempat konsentrasi penduduk untuk kegiatan ekonomi, sosial, administrasi dan pemerintahan. Sehingga, kurangnya daya tampung hunian bagi penduduk yang menetap di kota menyebabkan masyarakat membangun perumahan di daerah pinggiran kota (peri-urban). Akibatnya konversi lahan di wilayah ini semakin tahun juga semakin meningkat (Gambar 2). 
Sasaran pengguna pada perancangan bangunan ini adalah kalangan masyarakat menengah ke atas yang ingin mencari sebuah hunian lebih tenang di kawasan pinggir kota seperti peri-urban. Mereka adalah para pendatang yang banyak bekerja di wilayah urban.

\section{A. Permasalahan Desain}

Permasalahan desain dalam proyek rancang ini adalah membuat bangunan yang dapat mengakomodasi tingginya kebutuhan hunian di peri-urban tanpa melupakan produktivitas lahan. Selain itu, bangunan arsitektur juga harus menyesuaikan berbagai macam kebutuhan penghuni. (Gambar 3). Berikut kriteria desain yang ditentukan:

1. Bangunan arsitektur menyediakan fasilitas hunian serta area hijau produktif untuk menunjang produktivitas lahan.

2. Bangunan arsitektur menyediakan berbagai fasilitas pendukung selain hunian dan area hijau produktif dalam satu kesatuan bangunan.

\section{B. Pemilihan dan Deskripsi Tapak}

Sidoarjo merupakan salah satu wilayah peri-urban dengan pertumbuhan penduduk cukup tinggi. Menurut Badan Pusat Statistik (BPS) Jawa Timur, laju pertumbuhan penduduk Sidoarjo mencapai $1,6 \%$ per tahun dan menjadi kabupaten yang memiliki laju pertumbuhan penduduk tertinggi di Jawa Timur [3]. Pertumbuhan penduduk yang tinggi di Sidoarjo ternyata bukan dari angka kelahiran, melainkan karena tingginya tingkat urbanisasi. Hal tersebut membuat banyak penduduk pendatang membangun hunian-hunian baru di wilayah tersebut.

Lokasi yang dipilih untuk objek rancang berada di wilayah peri-urban Kabupaten Sidoarjo tepatnya di Jalan Taman Tiara, Kelurahan Pagerwojo, Kecamatan Buduran. Lahan merupakan lahan kosong yang berada di wilayah strategis dan berdekatan dengan fasilitas-fasilitas umum penunjang kebutuhan hunian seperti fasilitas perdagangan, jasa, pendidikan serta pusat pemerintahan. Selain itu, akses menuju area urban juga mudah karena dekat dengan pintu jalan tol Sidoarjo-Surabaya (Gambar 4).

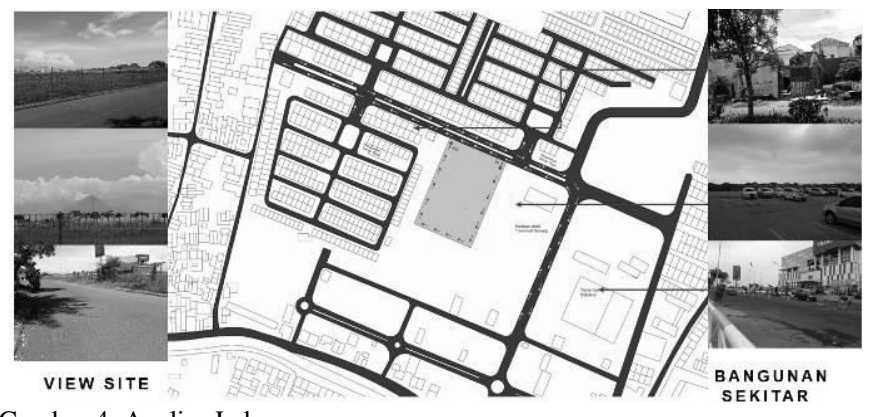

Gambar 4. Analisa Lahan.

\section{METODE PERANCANGAN}

Pendekatan desain yang digunakan adalah pendekatan hibrid. Hibrid adalah teori yang menggabungkan serta memperseyawakan (adaptif blending) dua atau lebih teori, fungsi dan bentuk yang berbeda menjadi suatu fungsi serta bentuk baru [4]. Pendekatan Arsitektur Hibrid digunakan untuk menyatukan dua fungsi utama dalam bangunan yaitu hunian dan area hijau produktif. Pendekatan ini digunakan agar kedua fungsi tersebut saling terkait dan saling menguntungkan dengan menyesuaikan kebutuhan masingmasing.

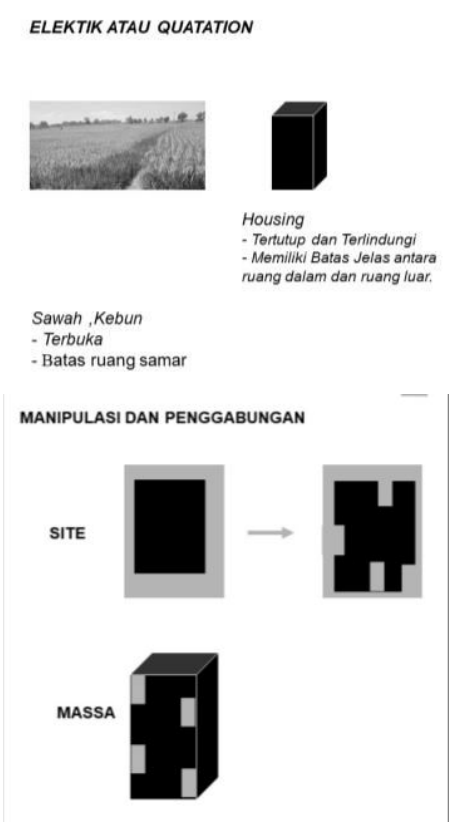

Gambar 5. Tahapan Hibrid.

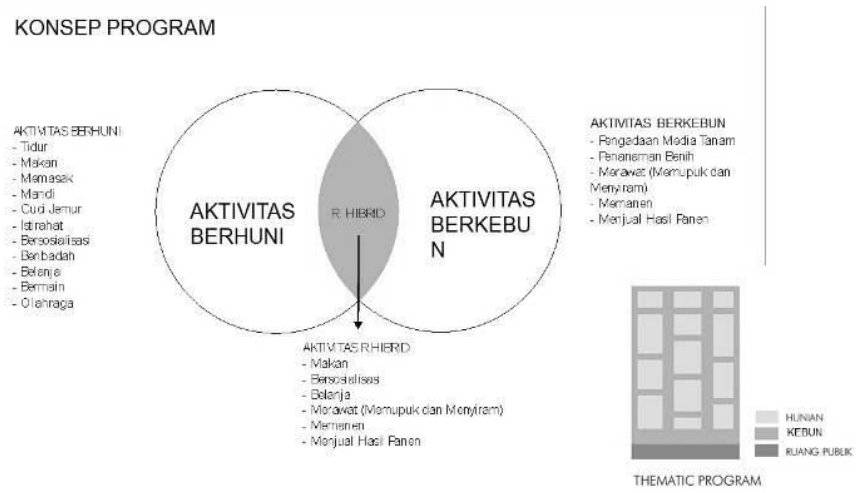

Gambar 6. Analisa Ruang Hibrid Dan Thematic Program.

Ada delapan kualitas untuk bangunan hibrid yaitu project scale, urban area density, function diversity, function scale, function integration, flexibility, vertical connections (that promote integration) dan Integrated Public Gathering Space [5]. Tidak semua kualitas tersebut harus diterapkan dalam perancangan, namun hal tersebut dapat mengukur penerapan arsitektur hibrid pada sebuah bangunan.

Mendesain bangunan hibrid dapat dilakukan melalui tahapantahapan sebagai berikut (Gambar 5):

1. Elektik atau quatation

Menelusuri dan memilih pembendaharaan bentuk dan elemen arsitektur dari masa lalu yang dianggap potensial untuk diangkat kembali atau telah mapannya makna yang diterima dan dipahami masyarakat. 


\section{Manipulasi atau modifikasi}

Elemen yang sudah terpilih selanjutnya dimanipulasi atau dimodifikasi dengan cara menggeser, mengubah dan atau memutarbalikkan makna yang telah ada.

3. Penggabungan

Penggabungan dan penyatuan beberapa elemen yang telah dimanipulasi atau dimodifikasi ke dalam desain.

Dalam bangunan hibrid, program dapat menurunkan berbagai bentuk bangunan. Namun ada dua kategori dasar dalam menggabungkan berbagai macam program di dalam bangunan, yaitu thematic program dan disparate program . Keduanya didasarkan pada kombinasi dan interaksi antar bagian dalam program bangunan. Dalam perancangan ini, penulis menggunakan metode thematic program sebagai cara untuk menggabungkan program bangunan, hal tersebut memungkinkan fungsi satu dengan lainnya saling ketergantungan dan saling berinteraksi dalam satu massa bangunan yang sama. Selain itu, penghuni maupun pengunjung dapat merasakan secara langsung suasana aktivitas berhuni dan berkebun yang menyatu di dalam satu bangunan yang sama.

Fungsi bangunan hibrid yang beraneka ragam dapat diperlihatkan secara langsung maupun tidak langsung ke dalam bentuk bangunan. Terdapat 3 jenis yaitu Fabric Hybrid Form, Graft Hybrid Form dan Monolith Hybrid Form [6]. Dalam perancangan ini penulis menggunakan metode Fabric Hybrid Form, yaitu salah satu bentuk bangunan hibrid yang mengeskpresikan program atau fungsi di dalamnya menggunakan material selimut bangunan [6]. Hal tersebut bertujuan agar masyarakat mengetahui bahwa fungsi bangunan tidak hanya sebagai hunian melainkan terdapat area hijau produktif yang dikembangkan di dalamnya (Gambar 7 dan 6).

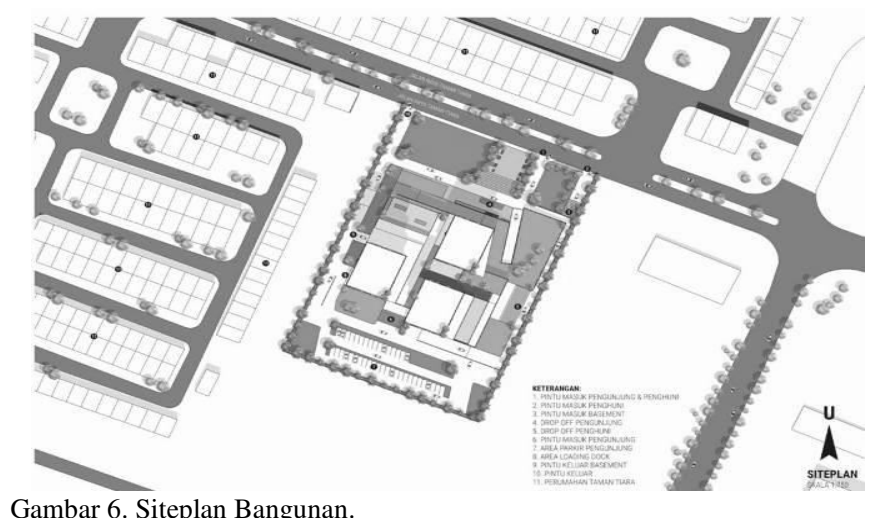

Gambar 6. Siteplan Bangunan.

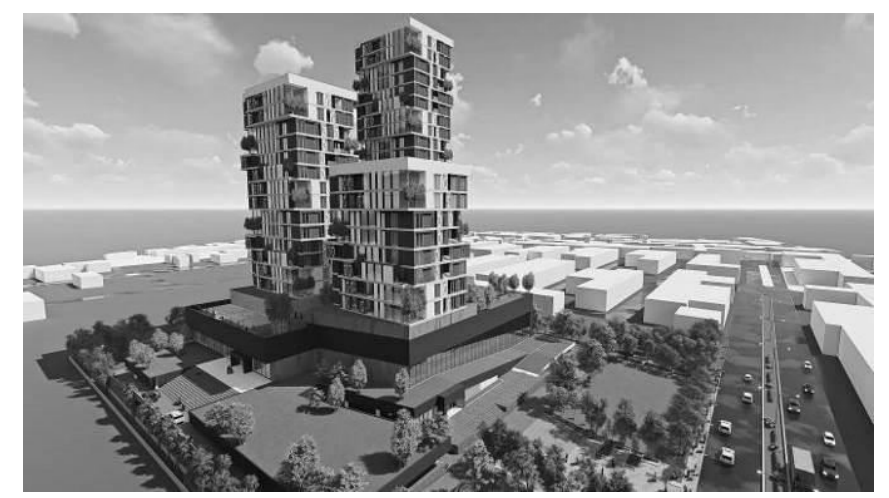

Gambar 7. Massa Bangunan.

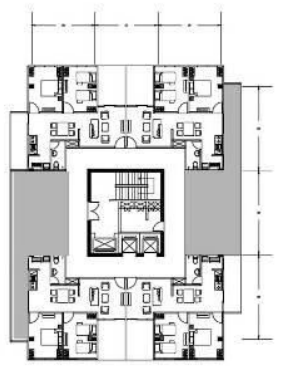

TOWER TIPE 1

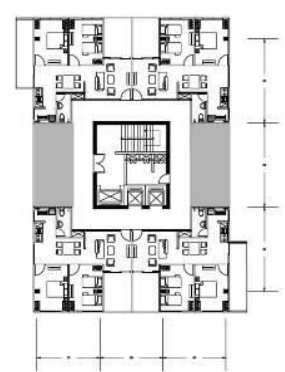

TOWER TIPE 2
Gambar 8 Thematic Program pada Tower
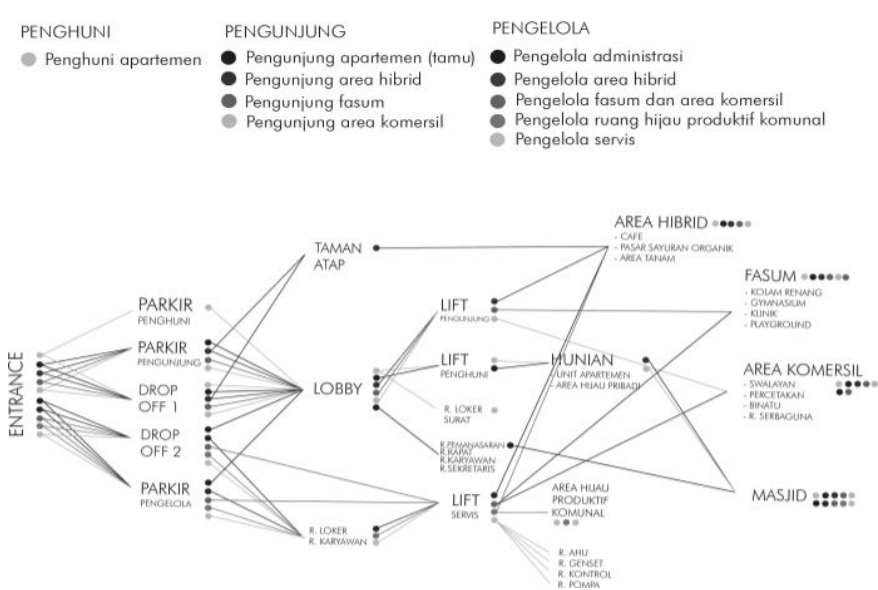

Gambar 9 Organisasi Ruang

\section{HASIL DAN EKSPLORASI}

Bangunan memiliki konsep utama membawa produktivitas lahan ke dalam hunian secara vertikal. Hibrid dari kedua hal tersebut diharapkan saling memberikan keuntungan yaitu penghuni dapat merasakan hunian yang hijau dan nyaman serta produktivitas lahan tetap terjaga. Penghuni juga memiliki kesempatan untuk mengembangkan aktivitas berkebun dalam unit mereka. Penerapan tahapan-tahapan hibrid dalam perancangan ini:

a.Ekletik : area berkebun merupakan area yang biasanya terbuka dan memiliki batas ruang sama, sedangkan untuk area berhuni merupakan ruang yang tertutup dengan batas yang jelas.

b. Manipulasi dan Penggabungan : Manipulasi dilakukan dengan menggabungkan dan menata area berkebun yang terbuka serta area berhuni yang tertutup, manipulasi dan penggabungan digunakan untuk menentukan penataan massa dan sitelan bangunan.

Tahapan dalam hibrid tersebut menjadi dasar dalam penataan penataan tapak/siteplan (Gambar 6) dan bentuk masa bangunan (Gambar 7).

\section{A. Zonifikasi dan Penataan Ruang}

Zonifikasi dilakukan agar kebutuhan fungsi yang ada dapat disesuaikan dengan konteks dan suasana yang diharapkan. Zona dibagi menjadi 3 yaitu area berhuni, area berkebun serta ruang-ruang fasilitas publik dan komersil. 
a. Area Berhuni

Membutuhkan kenyamanan, keamanan dan privasi. Kenyamanan didapatkan dari pencahayaan dan sirkulasi udara yang cukup. Elemen tumbuhan di dalam bangunan juga menimbulkan kenyamanan bagi penghuni.

b. Area Hijau Produktif

Area ini memerlukan cahaya matahari yang cukup untuk pertumbuhan tanaman. Sehingga bagian atau sisi bangunan yang digunakan harus menangkap cahaya matahari semaksimal mungkin. Zonifikasi area ini juga didasarkan pada jenis tanaman yang ditanam.

c. Area Ruang Publik dan Komersil

Berada di area yang paling mudah dijangkau oleh penghuni maupun non penghuni.

Penataan ruang hibrid pada bangunan menggunakan thematic program, yaitu area berhuni dan area berkebun diletakkan pada satu bangunan yang sama agar saling berdekatan dan terkait secara langsung (Gambar 8). Penataan ruang juga didasarkan pada kebutuhan matahari untuk aktivitas berkebun, sehingga lebih banyak menempatkan area tersebut pada sisi timur dan barat pada tower. Selanjutnya untuk menentukan posisi ruang menggunakan dasar diagram aktivitas dan penghuni yang diurutkan berdasarkan preseden (Gambar 9). Dalam bangunan juga terdapat ruang-ruang hibrid yang muncul yaitu ruang yang dapat mengakomodasi kedua aktivitas tersebut atau bahkan lebih secara bersama-sama dalam satu ruang (Gambar 10 dan 11).

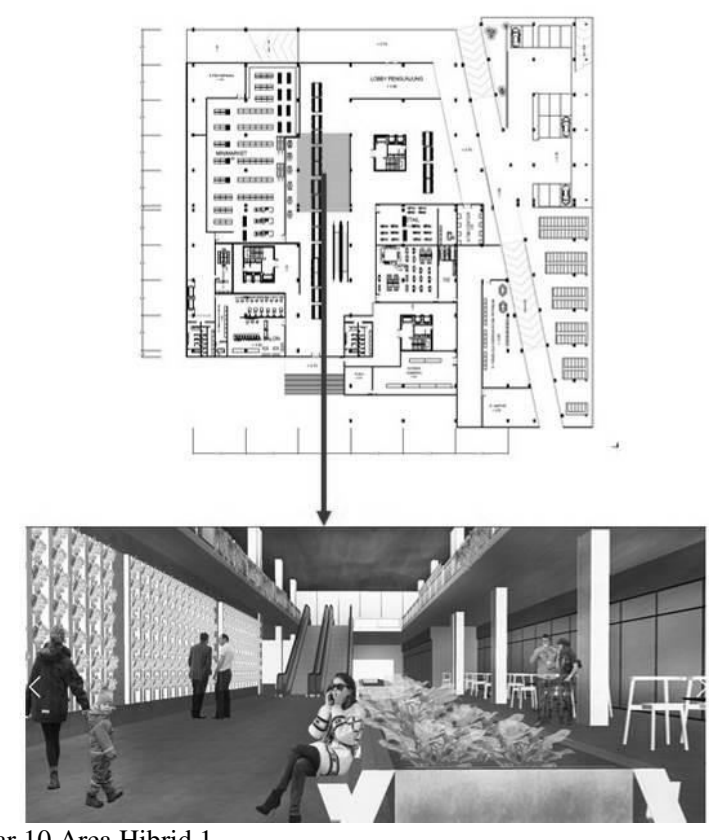

Gambar 10 Area Hibrid 1.

\section{B. Bentuk dan Material Bangunan}

Untuk transformasi bentuk, bangunan memiliki geometri dasar persegi yang disesuaikan dengan konteks lahan (Gambar 12). Hal tersebut berpengaruh pada efektifitas ruangan khususnya untuk unit-unit apartemen. Konsep bentuk Fabric Hybrid Form memberikan dampak pada material selimut bangunan. Material tersebut mengekspresikan fungsi di dalamnya, yaitu penggunan dinding bata ringan untuk area berhuni dan menggunakan material kaca untuk area berkebun (Gambar 13). Terdapat kisi-kisi alumunium yang digunakan sebagai shading device bangunan. Kisi-kisi alumunium dapat digeser sesuai kebutuhan penghuni dan hal tersebut menghadirkan ekspresi fasad bangunan berbeda setiap saat (Gambar 14).

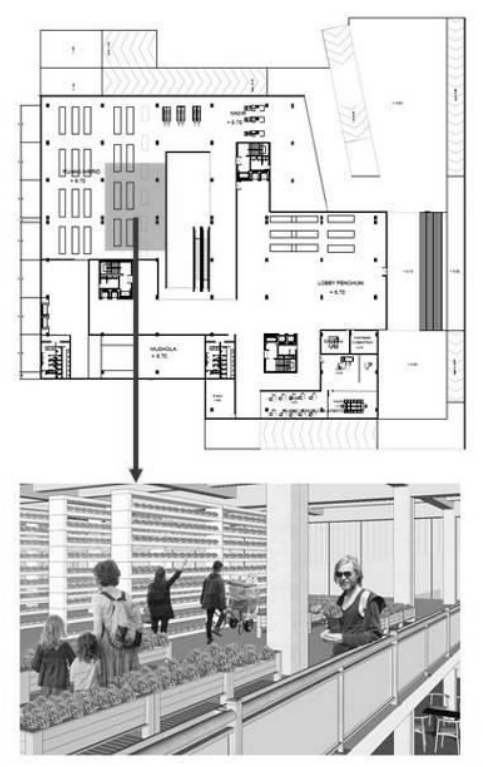

Gambar 11 Area Hibrid 2

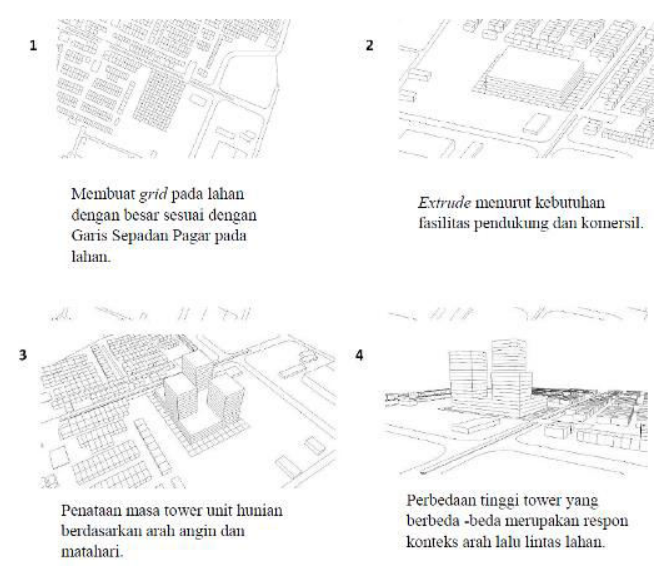

Gambar 12. Transformasi Bentuk.

\section{Sirkulasi Bangunan}

Bangunan apartemen ini merupakan bangunan yang mengakomodasi berbagai aktivitas, sehingga penataan sirkulasi tidak hanya dari aktivitas penghuni saja melainkan dari pengunjung luar. Perbedaaan sirkulasi untuk penghuni dan pengunjung menjadi sangat penting untuk menunjang privasi dan keamanan. Terdapat dua lobi utama untuk penghuni dan pengunjung. Transportasi vertikal penghuni menggunakan lift sedangkan pengunjung menggunakan escalator.

\section{Eksplorasi Makna}

Makna yang dihadirkan adalah penghuni maupun pengunjung menyadari tentang kedekatannya dengan alam dan tumbuhan. Sehingga setiap orang memiliki ketertarikan untuk berkebun secara mandiri di dalam unit masing-masing. Selain 
untuk estetika bangunan, penghadiran tanaman pada setiap sisi bangunan dapat menghadirkan suasana hijau produktif yang dirasakan sejak penghuni maupun pengunjung mulai memasuki area apartemen.

Area terbuka hijau produktif untuk aktivitas berkebun dibagi menjadi dua yaitu:

1. Aktivitas berkebun secara mandiri

Memungkinkan para penghuni dapat ikut menanam tanaman pada unit apartemen mereka. Aktivitas berkebun dalam unit dapat dijadikan hobi maupun dapat dikembangkan untuk produktivitas lahan (Gambar 15).

2. Aktivitas berkebun secara komunal

Terdapat area-area di dalam tower dan podium apartemen yang khusus digunakan untuk berkebun yang sifatnya lebih produktif dan dapat diperjualbelikan (Gambar 16 dan 17).

\section{E. Sistem Struktur}

Sistem Struktur yang digunakan adalah sistem struktur rigid dengan menggunakan kolom dan balok beton. Untuk lebih memperkuat bangunan terdapat core di 3 titik dan menggunakan sistem dillatasi kantilever (Gambar 18). Sistem struktur ini dapat memberikan fleksibilitas dalam penataan ruang, sehingga mendukung ruang-ruang hibrid yang terbentuk dalam bangunan.

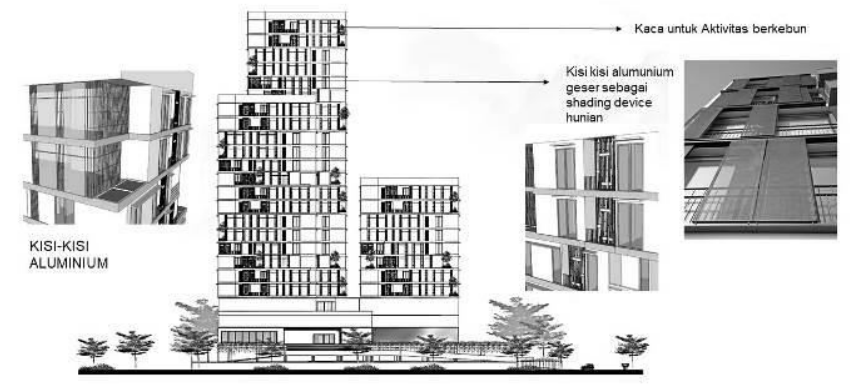

Gambar 14. Material Bangunan.

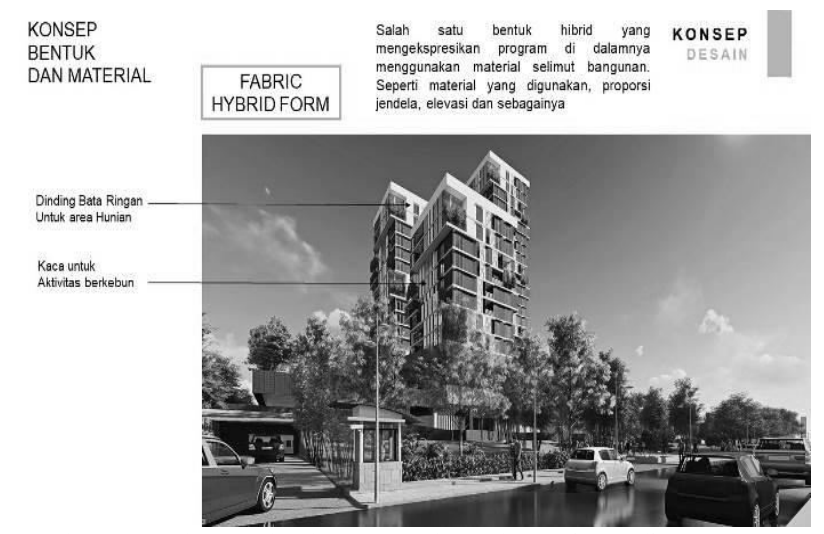

Gambar 13. Fabric Hybrid FormSumber : Ilustrasi Penulis, 2018.

\section{KESIMPULAN}

Berdasarkan isu tentang konversi lahan pertanian, apartemen produktif dijadikan sebagai respon arsitektur yang dapat mengakomodasi tingginya kebutuhan hunian di wilayah peri-urban tanpa melupakan produktivitas sebuah lahan. Dua fasillitas utama dalam bangunan apartemen adalah unit hunian dan area hijau produktif.

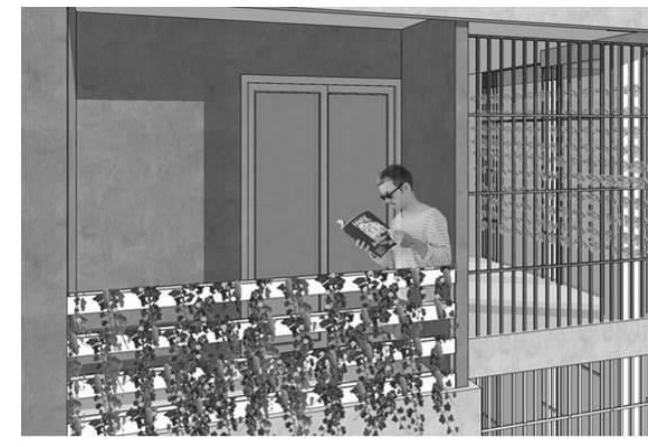

Gambar 15. Aktivitas Berkebun Mandiri.

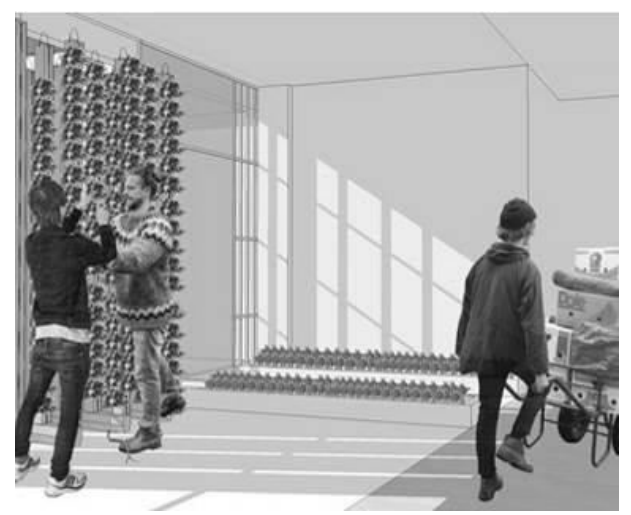

Gambar 16. Aktivitas Berkebun Komunal.

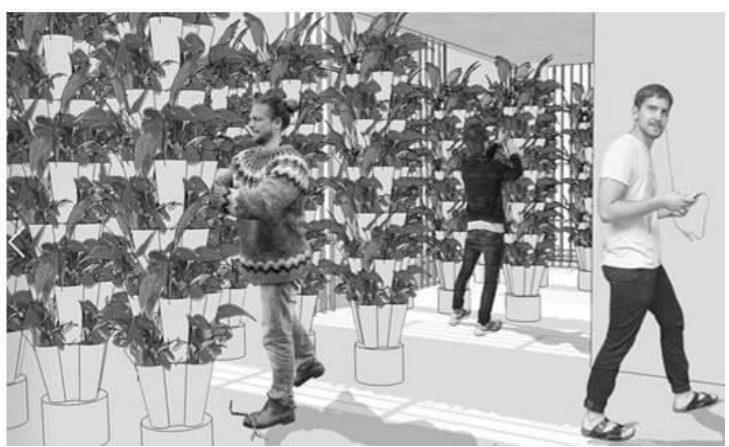

Gambar 17. Aktivitas Berkebun Komunal.
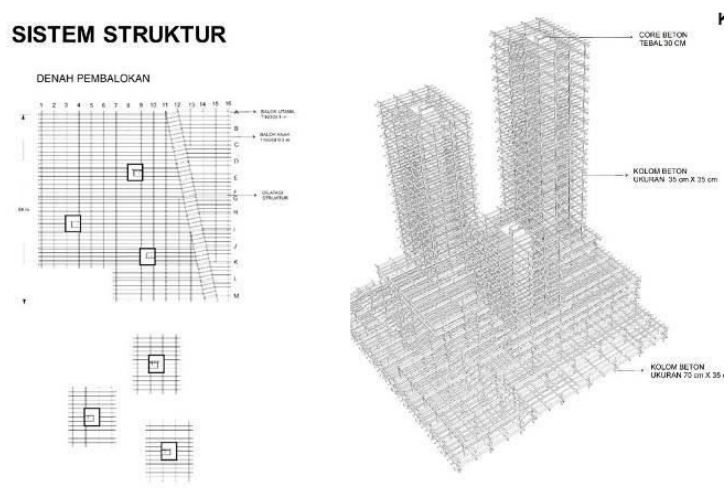

Gambar 18. Sistem Struktur.

Pendekatan hibrid digunakan untuk menyatukan kedua fungsi bangunan agar dapat menyatu dalam satu kesatuan tanpa melupakan kebutuhan dari masing-masing fungsi. Penulis menggunakan metode penggabungan program secara Thematic, sehingga ruang-ruang yang dihasilkan dapat 
memberikan suasana yang berbeda bagi penghuni. Penghuni dapat merasakan kedekatannya dengan alam dan tumbuhan serta penghuni memiliki ketertarikan untuk mengembangkan area hijau produktif dalam unit masing-masing. Metode Fabric Hybrid memberikan dampak pada bangunan, selain mengekspresikan fungsi di dalamnya, metode tersebut juga menambah estetika pada fasad. Dalam membuat sebuah bangunan hibrid, penentuan sirkulasi menjadi hal yang sangat penting karena akan berdampak pada kenyamanan pengguna bangunan khususnya untuk penghuni yang membutuhkan area privasi untuk sirkulasi.

Hasil dari perancangan ini adalah sebuah bangunan apartemen produktif yang dapat menyediakan hunian di wilayah peri-urban dengan area hijau produktif di dalamnya. Hibridisasi kedua fungsi tersebut membuka kesempatan penghuni untuk mengolah area hijau produktif secara mandiri dan berkontribusi dalam mempertahankan produktivitas lahan.

\section{DAFTAR PUSTAKA}

[1] T. Lestari, "Dampak Konversi Lahan Pertanian Bagi Taraf Hidup Petani," 2009.

[2] A. Fanny, "Analisis faktor-faktor yang mempengaruhi konversi lahan sawah ke penggunaan non pertanian di Kabbupaten Tangerang," 2005.

[3] Web Badan Pusat Statistik, "Jumlah Penduduk dan Laju Pertumbuhan Penduduk Menurut Kabupaten/Kota di Provinsi Jawa Timur, 2010, 2014 dan 2015," 2016. [Online]. Available: www.bps.go.id.

[4] R. Pujantara, "Tata Letak, Konfigurasi dan Interaksi Ruang pada Rancangan Arsitektur dengan Konsep Superimposisi dan Hibrid dalam Teori Function Follow Form," 2014.

[5] G. Robin, "An Exploration into The Quallities of True Hybrid Building," 2013.

[6] F. Joseph, Pamphlet Architecture no 11 Hybrid Building. New York: Princeton Architectural Press, 1985. 